\title{
Levels, seasonal variations, and health risks assessment of ambient air pollutants in the residential areas
}

\author{
W. C. Zhao $\cdot$ J. P. Cheng $\cdot$ Z. Y. Yu \\ Q. L. Tang $\cdot$ F. Cheng $\cdot$ Y. W. Yin $\cdot$ \\ W. H. Wang
}

Received: 22 June 2011/Revised: 6 December 2011 / Accepted: 7 March 2012/Published online: 13 February 2013

(C) Islamic Azad University (IAU) 2013

\begin{abstract}
People living in the urban area and the surrounding suburban area have disparities in exposure and health risks due to different levels of ambient air pollutants. The main objective of this study is to investigate the concentrations, seasonal variations, and related health risks of ambient air pollutants $\left(\mathrm{PM}_{10}, \mathrm{NO}_{2}\right.$, and $\left.\mathrm{SO}_{2}\right)$ in urban and suburban areas of Ningbo, China. The results showed that the average $\mathrm{PM}_{10}, \mathrm{NO}_{2}$, and $\mathrm{SO}_{2}$ concentrations in the urban area were $85.2,49.3$, and $37.4 \mu \mathrm{g} / \mathrm{m}^{3}$, which were $1.13,1.25$, and 1.41 times the values of the suburban area during the period of March 2009 to February 2010. For the potential health risk analysis, the residents have been divided into four age categories namely, infants, children ( 1 year), children ( $8-10$ years), and adults. The analysis took into account age-specific breathing rates, body weights for different age categories. The results showed that the potential health risks to respiratory disease for all age categories living in urban area were higher than those in suburban area.
\end{abstract}

Keywords Ambient air pollutants $\cdot$ Exposure $\cdot$ Health risks · Dose-response

\section{Introduction}

As the largest developing country in the world, China has achieved rapid economic development. However, this

W. C. Zhao · J. P. Cheng $(\bowtie) \cdot$ Z. Y. Yu •

Q. L. Tang · F. Cheng · Y. W. Yin · W. H. Wang

School of Environmental Science and Engineering,

Shanghai Jiao Tong University, 800 Dongchuan Road,

Shanghai 200240, People's Republic of China

e-mail: jpcheng@sjtu.edu.cn success comes at the cost of deterioration of the environment. Air pollution has become one of the top environmental concerns in China. Numerous studies worldwide have confirmed that both long- and short-term exposures to air pollutants are associated with increases in mortality and morbidity (Dockery 2009; Kan et al. 2008; Venners et al. 2003). According to a World Health Organization (WHO) assessment of the burden of disease due to air pollution, more than two million premature deaths each year can be attributed to the effects of urban outdoor air pollution and indoor air pollution (WHO 2005), and outdoor air pollution was associated with approximately 300,000 premature deaths per year in China (Cohen et al. 2005).

Ningbo $\left(28.51^{\circ}-30.33^{\circ} \mathrm{N}, 120.55^{\circ}-122.16^{\circ} \mathrm{E}\right)$, which is located in the middle of the coastal line of the Chinese Mainland and in the South of the Yangtze River Delta Region (YRDR), covers an area of $9,817 \mathrm{~km}^{2}$ with a population of 5.71 million. Ningbo is one of the largest cities in the YRDR and is also one of the most massively industrialized and urbanized cities in South China. Ningbo experiences a typical sub-tropic climate with mean annual precipitation of $1,480 \mathrm{~mm}$. The annual mean temperature is $16.4{ }^{\circ} \mathrm{C}$ with July as the hottest month $\left(28.0^{\circ} \mathrm{C}\right)$ and January as the coldest $\left(4.7^{\circ} \mathrm{C}\right)$. Prevailing wind direction is mainly southerly in summer and northerly in winter. During the past decade, Ningbo has undergone the most rapid development and urbanization in its history, and particulate matters (PMs), sulfur dioxide $\left(\mathrm{SO}_{2}\right)$, and nitrogen oxides (NOx) have become the major air pollutants.

Exposure to $\mathrm{PMs}, \mathrm{SO}_{2}$, and $\mathrm{NOx}$ was associated with deficits in lung function growth between 10 and 18 years of age (Gauderman et al. 2004). More importantly, the concentrations of $\mathrm{PMs}, \mathrm{SO}_{2}$, and $\mathrm{NOx}$ vary significantly in different areas of one city. The spatial variations have significant influence on the exposure. Therefore, it is 
necessary to use the PMs, $\mathrm{SO}_{2}$, and $\mathrm{NOx}$ concentrations measured at different areas of one city to assess the population exposure and the related health risks. To our best knowledge, few studies have studied the urban and suburban disparities of exposure to $\mathrm{PMs}, \mathrm{SO}_{2}$, and $\mathrm{NOx}$ and the related health risks. Thus, the objectives of this study are to investigate the disparities of exposure and health risks of pollutants $\left(\mathrm{PM}_{10}, \mathrm{NO}_{2}\right.$, and $\left.\mathrm{SO}_{2}\right)$ in the ambient air of the urban and suburban areas of Ningbo, and to provide new information about the relationship between air pollution and health risks in Ningbo, which may have implications for local environmental and social policies.

\section{Materials and methods}

$\mathrm{PM}_{10}, \mathrm{NO}_{2}$, and $\mathrm{SO}_{2}$ were continuously measured at three monitoring stations in the urban area, 16 monitoring stations in the suburban area of Ningbo (Fig. 1). The Monitoring stations 1-3 were located in the urban area, and Monitoring stations 4-19 were located in the suburban area. This study was initiated on March 1, 2009 and continued until February 28 2010. We made use of 20,805 daily records $\left(6,395\right.$ records for each pollutant) of $\mathrm{PM}_{10}$, $\mathrm{NO}_{2}$, and $\mathrm{SO}_{2}$. The arithmetic mean values of the daily records of the three monitoring stations in the urban area were considered as the pollutant concentrations of the urban area. Similarly, the arithmetic mean values of the daily records of the other 16 monitoring stations were considered as the pollutant concentrations of the suburban area. The daily records were obtained from Ningbo Environmental Protection Bureau.

The assessment of health risks of the population associated with inhalation exposure of $\mathrm{PM}_{10}, \mathrm{NO}_{2}$ and $\mathrm{SO}_{2}$ was based on the estimated dose rates and the lowest observed adverse effect levels (LOAELs). The Health risk assessment is age-specific. The population is divided into four age-specific categories namely, new born, children (1 year), children (8-10 years) and adults (Cerna et al. 1998). The dose rate for each pollutant has been estimated through the following expression (Kalaiarasan et al. 2009; Pandey et al. 2005).
Fig. 1 Location of Ningbo in China and locations of the monitoring stations

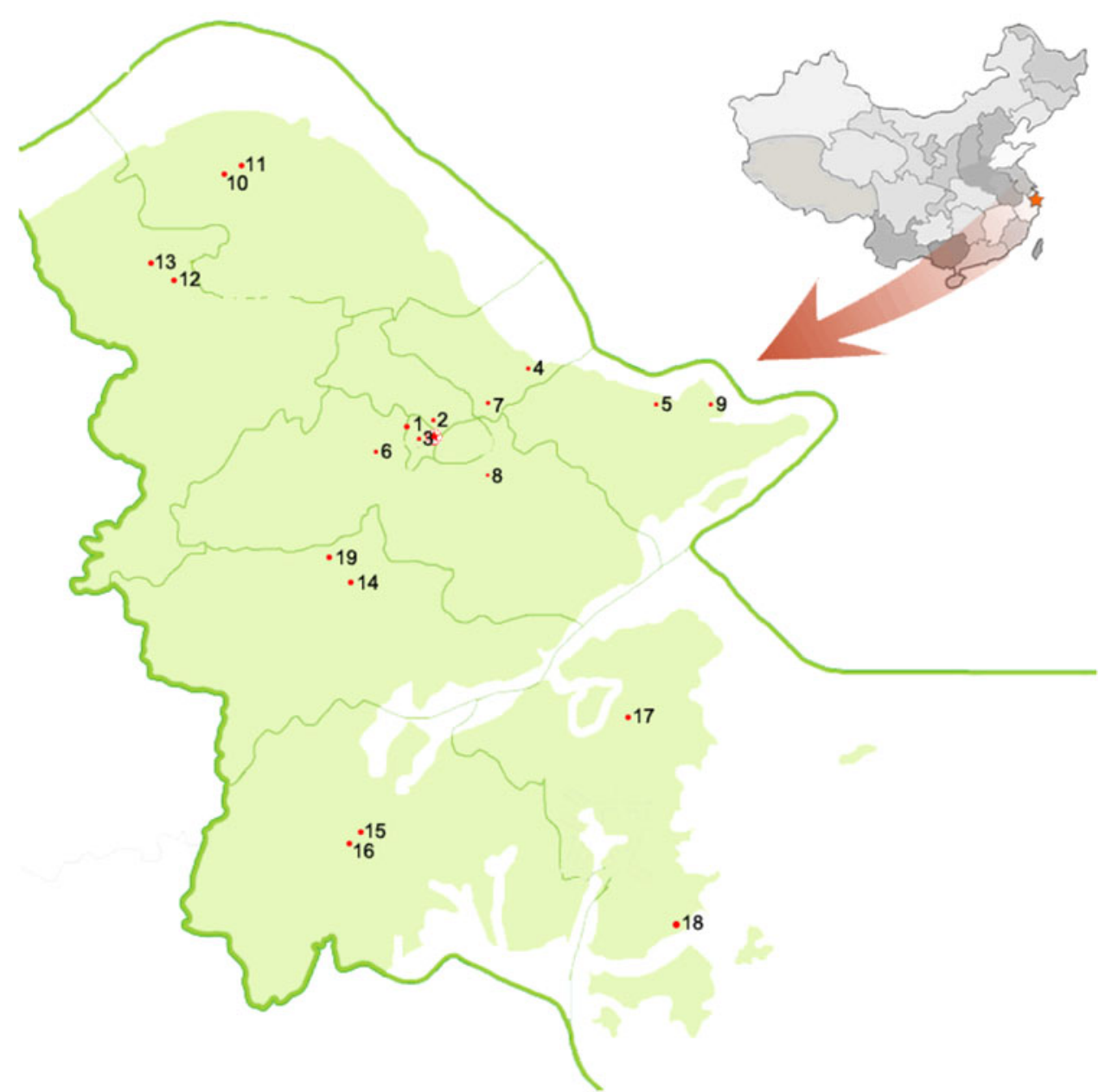


Dose rate $(D)=[\mathrm{BR} / \mathrm{BW}] \int_{0}^{24} C(t) \mathrm{OF}(t) \mathrm{d} t$,

where $D$ is the age-specific dose rate $(\mu \mathrm{g} / \mathrm{kg}), \mathrm{BR}$ is agespecific breathing rate $(\mathrm{L} / \mathrm{min}), \mathrm{BW}$ is age-specific body weight $(\mathrm{kg}), C(t)$ is the concentration of each pollutant $\left(\mu \mathrm{g} / \mathrm{m}^{3}\right)$; OF $(t)$ is occupancy factor (percentage of population likely to be in the building at a given interval of time). For each pollutant, we assume that the indoor and outdoor concentrations to be equal. Thus, $\mathrm{OF}(t)$ equals to 1. The uncertainties due to this assumption will be discussed hereinafter.

LOAELs are defined as the lowest tested doses of pollutants that have been reported to cause harmful (adverse) health effects on people or animal. LOAELs for $\mathrm{PM}_{10}$ and $\mathrm{SO}_{2}$ were taken from Cerna et al. (1998) as average of morbidity values. While for estimating the LOAEL value for $\mathrm{NO}_{2}$, the following dose-response model was constructed on the basis of data available in Neuberger et al. (2002):

$Y=103.6 X^{-0.1003}$,

where $Y$ is the response (in terms of \% end expiratory flow rates), $X$ is dose rates $(\mu \mathrm{g} / \mathrm{kg})$ for children estimated from the corresponding values given for $\mathrm{NO}_{2}$ in Neuberger et al. (2002). The dose value at which end expiratory flow rate becomes lower than $100 \%$ was taken as the LOAEL value for $\mathrm{NO}_{2}$ (Pandey et al. 2005).

Thus, the health risks have been defined using the following equation (Kalaiarasan et al. 2009; Castro et al. 2011):

Health risk $=[($ age-specific dose rate $) /$

(age-specific LOAEL)]

If the dose rate exceeds LOAEL, there may be concern for potential health risk of residents associated with inhalation exposure of $\mathrm{PM}_{10}, \mathrm{NO}_{2}$ and $\mathrm{SO}_{2}$. Health risk (HR) is dimensionless and useful for making relative comparisons.

\section{Results and discussion}

During the study period, the annual average concentrations and standard deviations of $\mathrm{PM}_{10}, \mathrm{NO}_{2}$ and $\mathrm{SO}_{2}$ in the suburban area were $75.2 \pm 40.4, \quad 39.6 \pm 19.6$, and $26.5 \pm 16.6 \mu \mathrm{g} / \mathrm{m}^{3}$, respectively, whereas the average concentrations and standard deviations in the urban area were $85.2 \pm 48.0,49.3 \pm 23.9$, and $37.4 \pm 19.1 \mu \mathrm{g} / \mathrm{m}^{3}$, respectively (Fig. 2). The concentrations in the urban and suburban areas were considerably higher than the concentration limits of the national ambient air quality standard

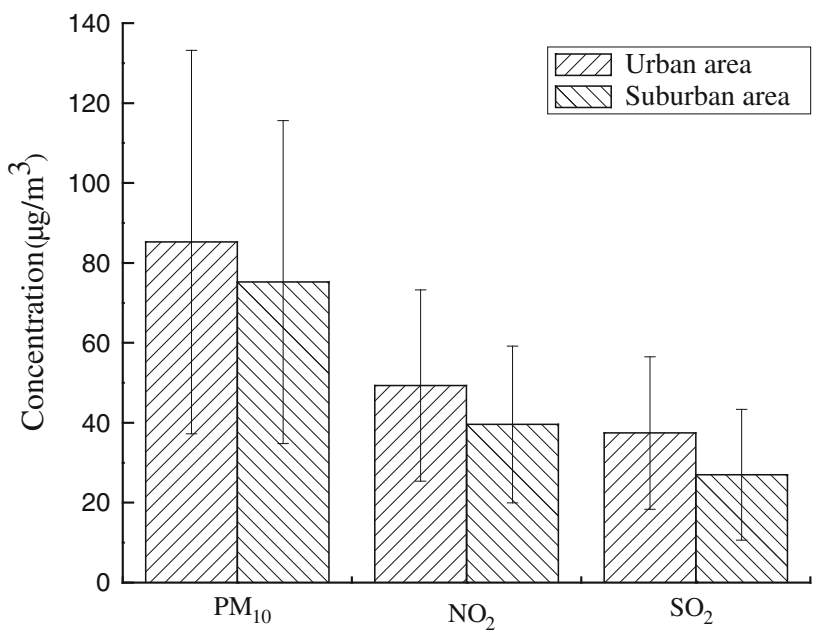

Fig. 2 Annual average concentrations of $\mathrm{PM}_{10}, \mathrm{NO}_{2}$ and $\mathrm{SO}_{2}$ in urban and suburban area of Ningbo, China

Grade I $\left(40,40\right.$, and $20 \mu \mathrm{g} / \mathrm{m}^{3}$ for $\mathrm{PM}_{10}, \mathrm{NO}_{2}$ and $\mathrm{SO}_{2}$, respectively MEP 2000) except the $\mathrm{NO}_{2}$ concentration in the suburban area, but lower than the national ambient air quality standard Grade II $\left(100,80\right.$, and $60 \mu \mathrm{g} / \mathrm{m}^{3}$ for $\mathrm{PM}_{10}$, $\mathrm{NO}_{2}$ and $\mathrm{SO}_{2}$, respectively, MEP 2000).

The $\mathrm{PM}_{10}$ concentrations were similar to those reported for other densely populated regions of China, such as Beijing (142 $\mu \mathrm{g} / \mathrm{m}^{3}$, Chan and Yao 2008) and Guangzhou (73 $\mu \mathrm{g} / \mathrm{m}^{3}$, Wan et al. 2011), but were substantially higher than those reported for big cities in Europe and East Asia, such as Dublin, Ireland $\left(18 \mu \mathrm{g} / \mathrm{m}^{3}\right.$, Environmental Protection Agency Ireland 2007) and Tokyo, Japan $\left(29 \mu \mathrm{g} / \mathrm{m}^{3}\right.$, Tokyo Metropolitan Government Bureau of General Affairs 2007). $\mathrm{NO}_{2}$ concentrations were also higher than those reported for big cities in Europe, such as Antwerp, Belgium $\left(25.2 \mu \mathrm{g} / \mathrm{m}^{3}\right.$, Stranger et al. 2009). A recent report showed that the average outdoor level for $\mathrm{NO}_{2}$ in Stockholm, Sweden was only $12.4 \mu \mathrm{g} / \mathrm{m}^{3}$ (Wichmann et al. 2010). The average $\mathrm{SO}_{2}$ concentrations in Ningbo were also very high, compared to the big cities in Europe and North America, such as Antwerp, Belgium $\left(4.8 \mu \mathrm{g} / \mathrm{m}^{3}\right.$, Stranger et al. 2009) and Boston, USA $\left(32.3 \mu \mathrm{g} / \mathrm{m}^{3}\right.$ in winter, $10.3 \mu \mathrm{g} / \mathrm{m}^{3}$ in summer, Brown et al. 2009).

The annual average concentrations of $\mathrm{PM}_{10}, \mathrm{NO}_{2}$ and $\mathrm{SO}_{2}$ in the urban area were $1.13,1.25$, and 1.41 times the values of the suburban area. Similar results were obtained in recent studies in India (Kulshrestha et al. 2009) and Italy (Dongarrà et al. 2010). The relatively high $\mathrm{PM}_{10}, \mathrm{NO}_{2}$ and $\mathrm{SO}_{2}$ levels in Ningbo could be attributed to both natural and anthropogenic sources. The increases in motor vehicles, urban construction, residential heating and industrial combustion contribute to the increase of $\mathrm{PM}_{10}, \mathrm{NO}_{2}$ and $\mathrm{SO}_{2}$ levels (Cao et al. 2009a).

For the investigation of the seasonal variations, the study period was divided into four seasons: spring (March 
2009 to May 2009), summer (June 2009 to August 2009), autumn (September 2009 to November 2009), and winter (December 2009 to February 2010). The significant seasonal variations of $\mathrm{PM}_{10}, \mathrm{NO}_{2}$ and $\mathrm{SO}_{2}$ were obtained during the study period (Fig. 3). For the suburban area, $\mathrm{PM}_{10}, \mathrm{NO}_{2}$ and $\mathrm{SO}_{2}$ were highest in winter $(100.1 \pm 51.4$,
$55.9 \pm 18.2$, and $40.5 \pm 19.0 \mu \mathrm{g} / \mathrm{m}^{3}$ ), followed by spring $\left(76.6 \pm 33.9,41.8 \pm 17.2\right.$, and $\left.28.8 \pm 12.1 \mu \mathrm{g} / \mathrm{m}^{3}\right)$, with lower concentrations in autumn $(72.9 \pm 34.5,38.6 \pm 16.5$, and $\left.24.8 \pm 14.1 \mu \mathrm{g} / \mathrm{m}^{3}\right)$ and summer $(51.8 \pm 21.2$, $22.3 \pm 8.8$, and $\left.14.2 \pm 4.8 \mu \mathrm{g} / \mathrm{m}^{3}\right)$. Nevertheless, for the urban area, $\mathrm{PM}_{10}, \mathrm{NO}_{2}$ and $\mathrm{SO}_{2}$ were highest in winter
Fig. 3 Seasonal variations of $\mathrm{PM}_{10}, \mathrm{NO}_{2}$ and $\mathrm{SO}_{2}$ in urban and suburban areas of Ningbo, China
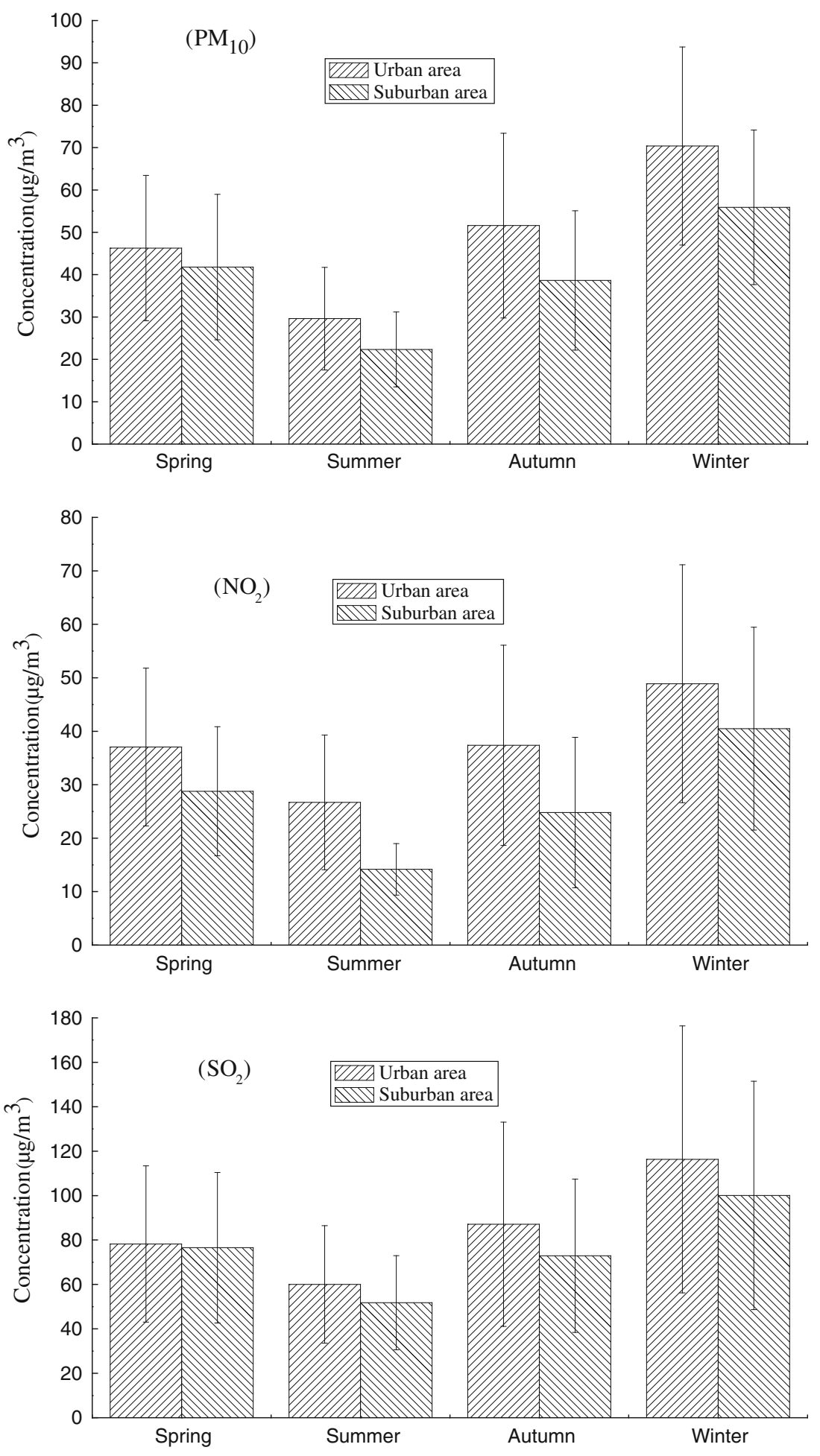
$\left(116.3 \pm 60.1,70.4 \pm 23.4\right.$, and $\left.48.9 \pm 22.3 \mu \mathrm{g} / \mathrm{m}^{3}\right)$, followed by autumn $(87.1 \pm 45.9, \quad 51.6 \pm 21.8$, and $37.4 \pm 18.7 \mu \mathrm{g} / \mathrm{m}^{3}$ ), with lower concentrations in spring $\left(78.2 \pm 35.2,46.3 \pm 17.2\right.$, and $\left.37.0 \pm 14.8 \mu \mathrm{g} / \mathrm{m}^{3}\right)$ and summer $(60.0 \pm 26.4,29.6 \pm 12.1$, and $26.7 \pm 12.6 \mu \mathrm{g} /$ $\left.\mathrm{m}^{3}\right)$. The different seasonal variations were likely due to a combination of meteorological conditions coupled with the different emission types of heating sources between the
Fig. 4 Dose rates for different age categories due to $\mathrm{PM}_{10}$, $\mathrm{NO}_{2}$, and $\mathrm{SO}_{2}$
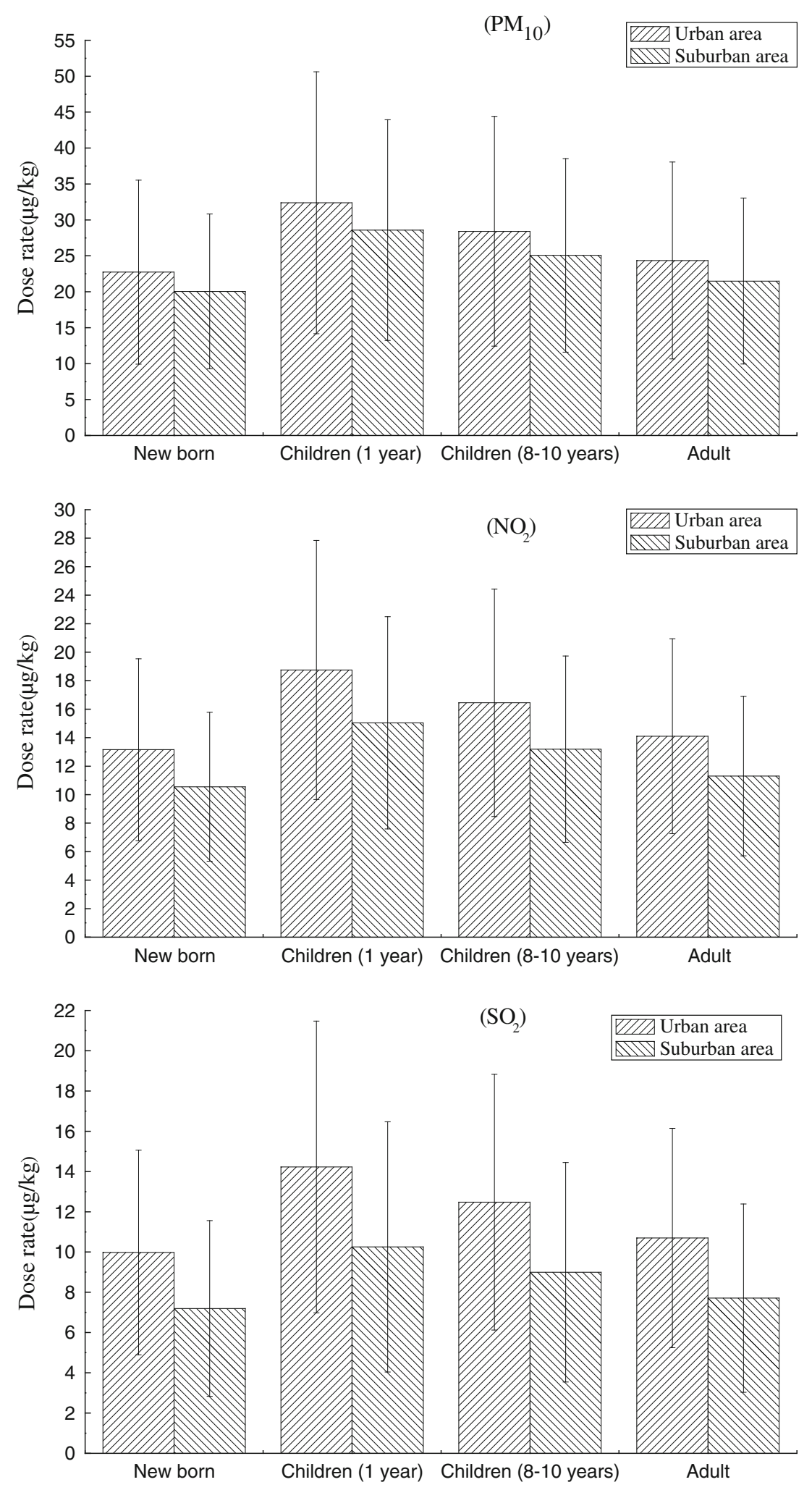
suburban and urban areas. The air parcels arriving in Ningbo in the summer and autumn were mainly from the East China Sea and carried clean air. On the other hand, air parcels arriving in Ningbo in winter and spring were from the northeast (Yellow Sea) to northwest (inland) directions and carried polluted air from Jiangsu province and Shanghai city (Feng et al. 2006; Li et al. 2011; Zhao et al. 2011), which made pollution in winter and spring more severe than summer and autumn. However, for the urban area, the atmospheric structure was comparatively stable, and temperature inversion often occurs in late autumn and winter, which made the dilution and diffusion of pollutants in the air more difficult, and thus pollution in autumn was more severe than spring (Cao et al. 2009b).

The dose rates, obtained for four age groups living in urban and suburban areas, are shown in Fig. 4. It is observed that dose rates for all age groups living in urban area were higher than those in suburban area, which indicated that the health risks for all age groups in urban area are higher than those in suburban area. At the same time, dose rates for children (1 year) were always higher than those for the other age groups, which indicated that the young children could have higher health risks. The absolute values of the dose rates depended on the concentrations of the pollutants and exposure profiles for different age categories. Children have a greater level of physical activity than adults; hence the intake of air into the lungs is much greater than adults per day (Salvi 2007). So children had higher dose rates than other age categories (Fig. 4). Similar results were obtained in other studies (Castro et al. 2011). However, health risk was estimated as a function which was proportional to the dose rates and inversely to the LOAEL values. The lower the value of pollutant-specific LOAEL, the higher is the health risk. Similarly, the higher is the dose rate, higher is the health risk. Comparison of HR values, which is shown in Table 1, indicated that health risks for all age groups in urban area were higher than those in suburban area. The HR values for all age groups in different seasons were also calculated, and the results showed that in each season, HR values for residents living in urban areas were always higher than those living in suburban areas.
Compared with adults, children are more vulnerable to particulates and gaseous pollutants in the air because of their immature immune systems. Moreover, children have differential abilities to metabolize and detoxify environmental agents and have an airway epithelium that is more permeable to inhaled air pollutants (Schwartz 2004). Due to the increasing emission from the motor vehicles and other sources, concentrations of $\mathrm{PM}_{10}, \mathrm{NO}_{2}$ and $\mathrm{SO}_{2}$ are greater near major roads. Children living in the urban area inhale more air pollutants than their fellows living in the suburban area, and increased adverse health effects among those living near busy roads in the urban area have been found (Zhu et al. 2002).

There is increasing evidence that exposure to higher levels of air pollution is associated with adverse health outcomes. A recent scientific statement from the American Heart Association concluded that short-term or long-term exposure to air pollution is associated with increased risk of cardiovascular disease and death (Brook et al. 2010). Moreover, high $\mathrm{PM}_{10}, \mathrm{SO}_{2}$ and $\mathrm{NO}_{2}$ levels could have combination of adverse health effects. Coal combustion was the major source of both particulate and gaseous pollutants in China, thus limiting our ability to separate the independent effect for individual pollutant. In summary, long-term exposure to outdoor air pollution was associated with increased health risks.

Exposure of $\mathrm{PM}_{10}, \mathrm{SO}_{2}$ and $\mathrm{NO}_{2}$ and related health risks for the residents living in the urban and suburban areas of Ningbo have been studied quantitatively. Our analysis had strengths and limitations. The estimation of exposure and health risks in this study was based on the outdoor air pollution. However, people spend approximately $90 \%$ of their time indoors (Monn 2001). Indoor exposure can be affected by many factors that influence indoor air pollution levels: activities of building occupants, building materials, furnishings and equipment, outdoor contamination levels, season, temperature, humidity, and ventilation rates. Thus, the estimation of indoor $\mathrm{PM}_{10}, \mathrm{SO}_{2}$, and $\mathrm{NO}_{2}$ levels is with great difficulty. In the past decade, a number of studies have investigated the indoor-outdoor $(\mathrm{I} / \mathrm{O})$ ratio of $\mathrm{PM}_{10}$, $\mathrm{SO}_{2}$, and $\mathrm{NO}_{2}$ levels (McCormack et al. 2008; Pekey et al. 2010; Mi et al. 2006; Kumar et al. 2007; Wichmann et al.

Table 1 Health risk values for different age categories due to $\mathrm{PM}_{10}, \mathrm{NO}_{2}$ and $\mathrm{SO}_{2}$

\begin{tabular}{|c|c|c|c|c|c|}
\hline Area & Pollutant & New born & Children (1 year) & Children (8-10 years) & Adult \\
\hline \multirow[t]{3}{*}{ Urban area } & $\mathrm{PM}_{10}$ & $1.55 \pm 0.87$ & $1.55 \pm 0.87$ & $1.03 \pm 0.58$ & $1.55 \pm 0.87$ \\
\hline & $\mathrm{NO}_{2}$ & $11.76 \pm 5.70$ & $11.78 \pm 5.71$ & $7.85 \pm 3.81$ & $11.79 \pm 5.72$ \\
\hline & $\mathrm{SO}_{2}$ & $1.88 \pm 0.96$ & $1.90 \pm 0.97$ & $1.26 \pm 0.64$ & $1.88 \pm 0.96$ \\
\hline \multirow[t]{3}{*}{ Suburban area } & $\mathrm{PM}_{10}$ & $1.36 \pm 0.73$ & $1.37 \pm 0.73$ & $0.91 \pm 0.49$ & $1.37 \pm 0.74$ \\
\hline & $\mathrm{NO}_{2}$ & $9.43 \pm 4.67$ & $9.45 \pm 4.68$ & $6.30 \pm 3.12$ & $9.46 \pm 4.68$ \\
\hline & $\mathrm{SO}_{2}$ & $1.33 \pm 0.84$ & $1.34 \pm 0.84$ & $0.89 \pm 0.56$ & $1.33 \pm 0.83$ \\
\hline
\end{tabular}


2010; Klinmalee et al. 2009). The differences between these outdoor values and the true exposures are an inherent and unavoidable type of measurement error. However, indoor levels do have strong associations with outdoor levels. Thus, the indoor and outdoor concentrations of $\mathrm{PM}_{10}, \mathrm{NO}_{2}$ and $\mathrm{SO}_{2}$ are assumed to be equal in our study and OF $(t)$ equals to 1 (Chao and Wong 2002; Morawska et al. 2001; Stranger et al.. 2009; Wang et al. 2006).

Despite the limitations and uncertainties, our study may provide new information on air pollution-related health effects in the urban and suburban areas of Ningbo, which may have reference significance for other parts of China.

\section{Conclusion}

This study provided the investigation of ambient air pollutants and the health risks for the local residents of Ningbo, China. The annual average concentrations of $\mathrm{PM}_{10}, \mathrm{NO}_{2}$ and $\mathrm{SO}_{2}$ in the urban area were higher than the suburban area. Due to a combination of meteorological conditions and the different emission types of heating sources in the urban and suburban areas, different seasonal variations of $\mathrm{PM}_{10}, \mathrm{NO}_{2}$ and $\mathrm{SO}_{2}$ were observed. The risk analysis showed that the potential health risks to respiratory disease for all age categories in urban area were higher than in suburban area.

Acknowledgments We wish to thank the reviewers of this article for their thoughtful suggestions and valuable insights. This work as financially supported by National Natural Science Foundation of China (No. 21177087) and the Shanghai Environmental Protection Bureau (SEPB) (No. 09-26).

\section{References}

Brook RD, Rajagopalan S, Pope CA, Brook JR, Bhatnagar A, DiezRoux AV, Holguin F, Hong Y, Luepker RV, Mittleman MA, Peters A, Siscovick D, Smith SC, Whitsel L, Kaufman JD (2010) Particulate matter air pollution and cardiovascular disease: an update to the scientific statement from the American Heart Association. Circulation 121(21):2331-2378

Brown KW, Sarnat JA, Suh HH, Coull BA, Koutrakis P (2009) Factors influencing relationships between personal and ambient concentrations of gaseous and particulate pollutants. Sci Total Environ 407(12):3754-3765

Cao J, Li W, Tan J, Song W, Xu X, Jiang C, Chen G, Chen R, Ma W, Chen B, Kan H (2009a) Association of ambient air pollution with hospital outpatient and emergency room visits in Shanghai, China. Sci Total Environ 407(21):5531-5536

Cao J, Shen Z, Chow JC, Qi G, Watson JG (2009b) Seasonal variations and sources of mass and chemical composition for $\mathrm{PM}_{10}$ aerosol in Hangzhou, China. Particuology 7(3):161-168

Castro D, Slezakova K, Delerue-Matos C, Alvim-Ferraz MDC, Morais S, Pereira MDC (2011) Polycyclic aromatic hydrocarbons in gas and particulate phases of indoor environments influenced by tobacco smoke: levels, phase distributions, and health risks. Atmos Environ 45(10):1799-1808

Cerna M, Jelinek R, Janoutova J, Kotesovec F, Benes I, Leixner M (1998) Risk assessment of the common air pollutants in Teplice, Czech Republic. Toxicol Lett 96-97:203-208

Chan CK, Yao X (2008) Air pollution in mega cities in China. Atmos Environ 42(1):1-42

Chao C, Wong K (2002) Residential indoor $\mathrm{PM}_{10}$ and $\mathrm{PM}_{2.5}$ in Hong Kong and the elemental composition. Atmos Environ 36(2):265-277

Cohen AJ, Anderson HR, Ostro B, Pandey KD, Krzyzanowski M, Künzli N, Gutschmidt K, Pope A, Romieu I, Samet JM, Smith K (2005) The global burden of disease due to outdoor air pollution. J Toxicol Environ Health Part A 68(13-14):1301-1307

Dockery DW (2009) Health effects of particulate air pollution. Ann Epidemiol 19(4):257-263

Dongarrà G, Manno E, Varrica D, Lombardo M, Vultaggio M (2010) Study on ambient concentrations of $\mathrm{PM}_{10}, \mathrm{PM}_{10-2.5}, \mathrm{PM}_{2.5}$ and gaseous pollutants. Trace elements and chemical speciation of atmospheric particulates. Atmos Environ 44(39):5244-5257

Environmental Protection Agency Ireland (2007) Air quality in Ireland 2006. http://www.epa.ie/downloads/pubs/air/quality/epa_air_quality_ report_2006.pdf

Feng JL, Chan CK, Fang M, Hu M, He L, Tang X (2006) Characteristics of organic matter in $\mathrm{PM}_{2.5}$ in Shanghai. Chemosphere 64(8):1393-1400

Gauderman WJ, Avol E, Gilliland F, Vora H, Thomas D, Berhane K, McConnell R, Kuenzli N, Lurmann F, Rappaport E, Margolis H, Bates D, Peters J (2004) The effect of air pollution on lung development from 10 to 18 years of age. N Engl J Med 351(11): $1057-1067$

Kalaiarasan M, Balasubramanian R, Cheong KWD, Tham KW (2009) Traffic-generated airborne particles in naturally ventilated multistorey residential buildings of Singapore: vertical distribution and potential health risks. Build Environ 44(7):1493-1500

Kan H, London SJ, Chen G, Zhang Y, Song G, Zhao N, Jiang L, Chen B (2008) Season, sex, age, and education as modifiers of the effects of outdoor air pollution on daily mortality in Shanghai, China: the Public Health and Air Pollution in Asia (PAPA) Study. Environ Health Perspect 116(9):1183-1188

Klinmalee A, Srimongkol K, Kim ONT (2009) Indoor air pollution levels in public buildings in Thailand and exposure assessment. Environ Monit Assess 156(1-4):581-594

Kulshrestha AP, Satsangi PG, Masih J, Tanej A (2009) Metal concentration of $\mathrm{PM}_{2.5}$ and $\mathrm{PM}_{10}$ particles and seasonal variations in urban and rural environment of Agra, India. Sci Total Environ 407(24):6196-6204

Kumar R, Nagar JK, Kumar H, Kushwah AS, Meena M, Kumar P, Raj N, Singhal MK, Gaur SN (2007) Association of indoor and outdoor air pollutant level with respiratory problems among children in an industrial area of Delhi, India. Arch Environ Occup Health 62(2):75-80

Li L, Chen C, Fu J, Huang C, Streets D, Huang H, Zhang G, Wang Y, Jang C, Wang H, Chen Y, Fu J (2011) Air quality and emissions in the Yangtze River Delta, China. Atmos Chem Phys 11(4): $1621-1639$

McCormack MC, Breysse PN, Hansel NN, Matsui EC, Tonorezos ES, Curtin-Brosnan J, Williams DL, Buckley TJ, Eggleston PA, Diettea GB, Diette GB (2008) Common household activities are associated with elevated particulate matter concentrations in bedrooms of inner-city Baltimore pre-school children. Environ Res 106(2):148-155

MEP (2000) Ambient air quality standard. http://bz.mep.gov.cn/bzwb/ dqhjbh/dqhjzlbz/199612/t19961206_67502.htm

Mi YH, Norbäck D, Tao J, Mi YL, Ferm M (2006) Current asthma and respiratory symptoms among pupils in Shanghai, China: 
influence of building ventilation, nitrogen dioxide, ozone, and formaldehyde in classrooms. Indoor Air 16(6):454-464

Monn C (2001) Exposure assessment of air pollutants: a review on spatial heterogeneity and indoor/outdoor/personal exposure to suspended particulate matter, nitrogen dioxide and ozone. Atmos Environ 35(1):1-32

Morawska L, He C, Hitchins J, Gilbert D, Parappukkaran S (2001) The relationship between indoor and outdoor airborne particles in the residential environment. Atmos Environ 35(20):3463-3473

Neuberger M, Moshammer H, Kundi M (2002) Declining ambient air pollution and lung function improvement in Austrian children. Atmos Environ 36(11):1733-1736

Pandey JS, Kumar R, Devotta S (2005) Health risks of $\mathrm{NO}_{2}, \mathrm{SPM}$ and $\mathrm{SO}_{2}$ in Delhi (India). Atmos Environ 39(36):6868-6874

Pekey B, Bozkurt ZB, Pekey H, Doĝan G, Zararsiz A, Efe N, Tuncel G (2010) Indoor/outdoor concentrations and elemental composition of $\mathrm{PM}_{10} / \mathrm{PM}_{2.5}$ in urban/industrial areas of Kocaeli City, Turkey. Indoor Air 20(2):112-125

Salvi S (2007) Health effects of ambient air pollution in children. Paediatr Respir Rev 8(4):275-280

Schwartz J (2004) Air pollution and children's health. Pediatrics 113(4 II), 1037-1043.

Stranger M, Potgieter-Vermaak SS, Grieken RV (2009) Particulate matter and gaseous pollutants in residences in Antwerp, Belgium. Sci Total Environ 407(3):1182-1192
Tokyo Metropolitan Government Bureau of General Affairs (2007) Tokyo Statistical Yearbook 2006. http://www.toukei.metro. tokyo.jp/tnenkan/tn-eindex.htm

Venners SA, Wang B, Xu Z, Schlatter Y, Wang L, Xu X (2003) Particulate matter, sulfur dioxide, and daily mortality in Chongqing, China. Environ Health Perspect 111(4):562-567

Wan J, Lin M, Chan C, Zhang Z, Engling G, Wang X, Chan I, Li S (2011) Change of air quality and its impact on atmospheric visibility in central-western Pearl River Delta. Environ Monit Assess 172(1-4):339-351

Wang X, Bi X, Sheng G, Fu J (2006) Hospital indoor $\mathrm{PM}_{10} / \mathrm{PM}_{2.5}$ and associated trace elements in Guangzhou, China. Sci Total Environ 366(1):124-135

WHO (2005) Air quality guideline global update. http://www. euro.who.int/_data/assets/pdf_file/0005/78638/E90038.pdf

Wichmann J, Lind T, Nilsson MA-M, Bellander T (2010) PM $_{2.5}$, soot and $\mathrm{NO}_{2}$ indoor-outdoor relationships at homes, pre-schools and schools in Stockholm, Sweden. Atmos Environ 44(36):4536-4544

Zhao W, Cheng J, Guo M, Cao Q, Yin Y, Wang W (2011) Ambient air particulate matter in the yangtze river delta region, China: spatial, annual, and seasonal variations and health risks. Environ Eng Sci 28(11):795-802

Zhu Y, Hinds WC, Kim S, Sioutas C (2002) Concentration and size distribution of ultrafine particles near a major highway. J Air Waste Manag Assoc 52(9):1032-1042 